\title{
Des figures hors cadre L'émergence du corps sculpté dans l'architecture de la Renaissance en France
}

\author{
Sarah Munoz \\ Université de Lausanne, Suisse
}

\begin{abstract}
Sculpted Renaissance medallions, inspired by ancient coins and clipeatae imagines, were developed in French monuments from around 1500 to 1550. First applied to the surface of the wall and restricted to a face, they showed, around 1530-1540, transformations related to the adaptation and variation of the body in the decoration. Characters in very high relief, sometimes represented up to the hips, were multiplied, freed from their frame, addressing the viewer and creating illusion games when they were placed in false windows. These decorations thus testify to the relationship between structure and sculpture and the growing humanisation of the wall.
\end{abstract}

Keywords Medallions. Busts. Portraits. Ornament. Renaissance.

Sommaire 1 Introduction. - 2 Les têtes en médaillon et leurs variations. - 3 Émergence du buste et affranchissement du cadre. - 4 Affirmation du corps dans le décor : jeux d'illusion et théâtralité. - 5 Conclusion.

\section{Introduction}

$\mathrm{Au}$ cœur de l'abondante sculpture décorative qui enrichit nombre de monuments français dans la première moitié du XVIe siècle, les têtes en médaillon constituaient un motif de choix, un gage de modernité et de culture particulièrement apprécié. ${ }^{1}$ En France, ces ornements apparurent dès les prémices du décor all'antica, dans les années 1500, et disparurent autour de 1550, alors qu'une architecture davantage fondée sur les ordres classiques, qui étaient diffusés par les traités d'architecture, fut développée. ${ }^{2}$ Consistant en la représentation d'un visage ou d'un buste mis en valeur par un cadre circulaire, inspirée des monnaies et des imagines clipeatae, les têtes en médaillon se révèlent singulières et significatives au sein de l'ensemble des motifs ' à l'antique ' en raison de leur caractère figuratif. Elles participent ainsi de l'essor du portrait à la Renaissance et répondent à l'impor-

1 Munoz 2016

2 Voir par exemple Martin 1547; Deswarte-Rosa 2004.

$\begin{array}{lll} & \text { Peer review } & \\ \text { Edizioni } & \text { Submitted } & 2020-07-09 \\ \text { Ca'Foscari } & \text { Accepted } & 2020-10-14 \\ & \text { Published } & 2020-12-11\end{array}$

Open access

(c) 2020 | ()( Creative Commons Attribution 4.0 International Public License

Citation Munoz, S. (2020). "Des figures hors cadre. L'émergence du corps sculpté dans l'architecture de la Renaissance". Venezia Arti, n.s., 29, 195-214. 
tance que prenait l'individu qui se « découvr[ait]» lui-même « dans ses faits et gestes ${ }^{3}{ }^{3}$

Le goût pour les visages et bustes ornementaux dans l'architecture du Moyen Âge en France pourrait en partie expliquer le succès que connurent ces motifs dans les monuments de la Renaissance. L'art roman témoignait déjà de jeux d'illusion mettant en scène des personnages sculptés qui animaient l'élévation ou les portails. De nombreux visages occupaient les modillons, les chapiteaux, les culots et les clefs de voûte dans l'architecture religieuse. En conclusion de son étude sur la tête de feuilles, Pierre-Yves Le Pogam soulignait ainsi « l'humanisation universelle du décor » déjà présente dans l'art gothique. ${ }^{4}$

Si deux types de médaillons sont généralement évoqués, à savoir ceux présentant des visages de profil en bas-relief, qui rappellent les monnaies anciennes, et ceux montrant des têtes ou bustes de

\section{Les têtes en médaillon et leurs variations}

$\mathrm{Au}$ cours des quatre premières décennies du XVIe siècle, les médaillons témoignèrent de variations qui tendent à montrer des transformations liées à la mise en valeur du visage. L'observation de la sculpture décorative des édifices qui sont assurément datés permet d'analyser la place accordée à la figure humaine et l'évolution de cette considération.

Les monuments français de la Renaissance furent d'abord enrichis de profils en bas-relief, représentant des personnages évocateurs de l'Antiquité, taillés dans des médaillons plus ou moins imposants. Cette typologie répondait au goût grandissant pour la numismatique et s'inscrivait dans un contexte humaniste. Certains visages étaient par exemple inspirés de ceux d'empereurs romains vus sur des monnaies ou dans les ' livres de médailles ' qui se multipliaient au XVIe siècle. ${ }^{6}$ Ce goût trouvait sa source dans plusieurs monuments que les Français avaient pu admirer dans le royaume de Naples, la République de Gênes et le Duché de Mi- face en haut-relief, inspirés des imagines clipeatae, les portraits présents dans la sculpture décorative dessinent cependant des personnages aux formes plus diverses et parfois complexes. Du visage vu de profil inséré dans un cercle à la figure à micorps en très haut-relief, les mêmes emplacements et un goût similaire pour l'humain sont observés. Cet ornement comprend ainsi des variations aussi multiples que des profils d'appliques, des médaillons contenant des visages vus de profil, des têtes présentées de face ou des bustes en haut-relief, des effigies contenues dans d'autres types d'encadrements ou encore des figures à mi-corps autonomes. À la différence de la plupart des motifs 'à l'antique ', qui connurent des variations mais peu d'évolution formelle, les médaillons, de leur apparition à leur raréfaction durant la première moitié du XVIe siècle, gagnèrent en autonomie et en relief. ${ }^{5}$

lan. De tels profils décorent par exemple l'arc-detriomphe du Castelnuovo de Naples, la façade de la chartreuse de Pavie, et les portails du palais Doria à Gênes et du palais Vimercati à Milan. ${ }^{7}$ En France, des profils 'à l'antique ', notamment des séries d'effigies impériales, furent ainsi plaqués à la manière de médailles probablement au château du Verger de Seiches-sur-le-Loir dès 1502, ${ }^{8}$ à celui de Gaillon vers 1508-1509 [fig. 1], ${ }^{9}$ de Nançay vers 1508$1510,{ }^{10}$ et de Meillant avant $1511 .{ }^{11}$ Ces ornements en marbre furent taillés par des Italiens qui contribuèrent à introduire les motifs de la Renaissance en France. Il s'agit alors d'œuvres réalisées en Italie puis exportées, ou de reliefs sculptés au sein d'ateliers italiens itinérants ou installés en France.

Les profils furent ensuite diffusés dans la sculpture décorative de plusieurs monuments élevés dans les années 1510 dans diverses provinces. En Anjou, il apparaît au portail sud de la chapelle du château de Thouars, de 1503-1516. ${ }^{12}$ En Touraine,

3 Chastel 1989, 221.

4 Le Pogam 2007, 42.

5 Trois cartes placées en annexe de cet article permettent de situer les villes françaises évoquées et de percevoir la diffusion des multiples formes que prenaient les médaillons et bustes durant la première moitié du XVIe siècle.

6 Fulvio 1517; Huttich 1525.

7 Bedocchi Melucci 1988; Burnett, Schofield 1997, 1998; Di Battista 1998-1999; Schofield 1999; Passoni, Stoppa 2000.

8 Guillaume 2003, 144.

9 Bresc-Bautier 2007, 2010

10 Chancel-Bardelot 2002, 21-2; Bresc-Bautier 2010, 21

11 Jestaz 2003, 295.

12 Guillaume 2004b, 311-12. 
plusieurs profils enrichirent le portique de l'hôtel Jacques de Beaune de Tours en 1518, ${ }^{13}$ tandis qu'en Charente, ce type de portrait fut mis à l'honneur dans le 'balcon du roi ' du château de Cognac, remanié à partir de la même année. ${ }^{14}$ Dans le Quercy, ces effigies furent employées à l'église Saint-PierreSaint-Paul et au château de Lagrézette, tous deux situés à Caillac et remaniés entre 1515 et 1520 pour l'archidiacre Gilibert de Massaut. ${ }^{15}$

Par la suite, dans les années 1520, de nombreux monuments témoignèrent du recours aux profils dans la plupart des provinces. Dans l'Orléanais, ils furent sculptés sous la forme de petits médaillons pour entourer des baies, sur la façade des Loges du château de Blois, remanié de 1515 à $1524 .{ }^{16}$ De plus grands visages furent employés, de nouveau dans le Quercy, au château de Montal (à Saint-Jean-Lespinasse), sous les marches de l'escalier portant les dates 1520 et $1521 .{ }^{17}$ Dans l'architecture bourguignonne, les profils furent introduits dans la première cour de l'hôtel Pétral, à Beaune, en 1522. ${ }^{18}$ Plus au Nord, en Champagne, les façades sur cour de l'hôtel Le Vergeur, à Reims, furent enrichies de profils en médaillon, vers $1523 .{ }^{19}$ À Tours, ce fut également à cette date que fut achevée la construction de l'hôtel Babou de la Bourdaisière, orné de portraits impériaux. ${ }^{20}$ Les exemples d'édifices ornés de profils taillés dans des médaillons, dont les constructions sont assez précisément datées, se multiplièrent encore en France jusqu'à la fin des années 1520 : au château d'Azay-le-Rideau avant 1522,, à la collégiale des Roches-Tranchelion, à Avon-les-Roches, avant 1524, ${ }^{22}$ au château de Bonnivet de Vendeuvre-du-Poitou et à celui des Granges-Cathus de Talmont-Saint-Hilaire vers $1525,{ }^{23}$ au château de La Rochefoucauld avant 1528, ${ }^{24}$ à l'hôtel Bérenguier-Maynier de Toulouse dans ces mêmes années, ${ }^{25}$ ou encore sur la façade de la maison Jaillet de Paray-le-Monial vers $1525-1528,{ }^{26}$ où se trouvent vingt-huit profils. Les

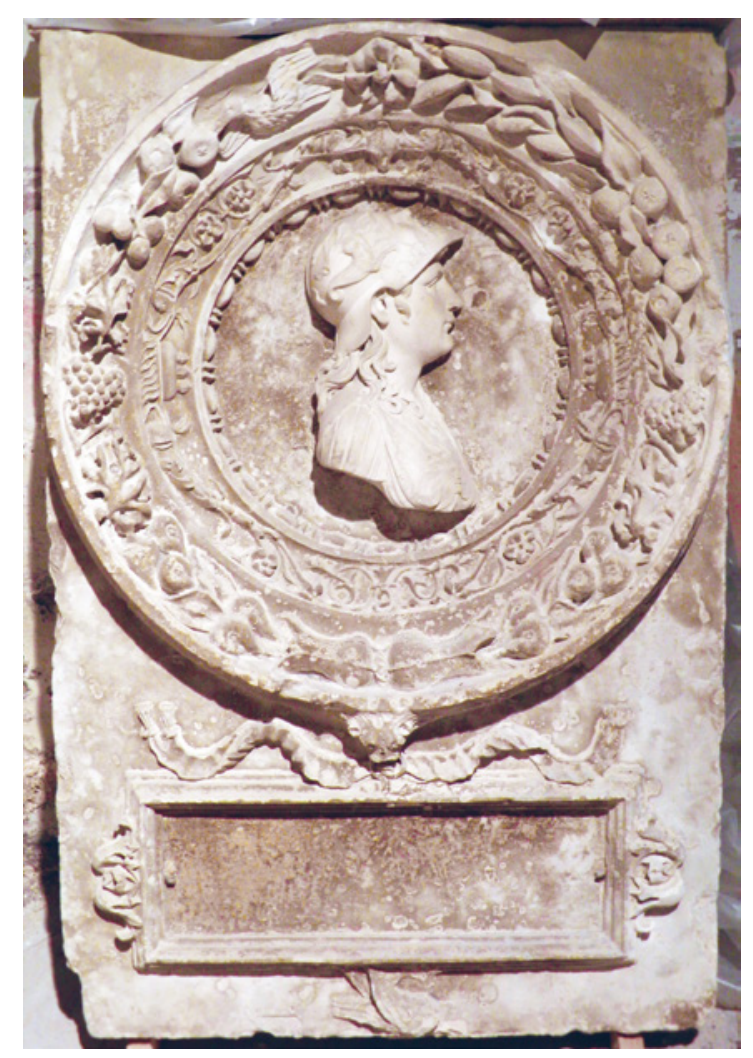

Figure 1 Profil d'applique et cadre provenant du château de Gaillon. 1508-1509. Pierre et marbre. Château de Gaillon, dépôt lapidaire

profils sculptés semblent se raréfier après les décennies 1510-1520. Les bas-reliefs insérés dans la galerie dite François I ${ }^{\text {er }}$ du château d'Oiron, après 1541, font par exemple partie des rares médaillons de cette typologie parmi les monuments les mieux datés. ${ }^{27}$

À partir de 1530 environ, l'insertion de têtes et bustes vus de face, surgissant plus ou moins

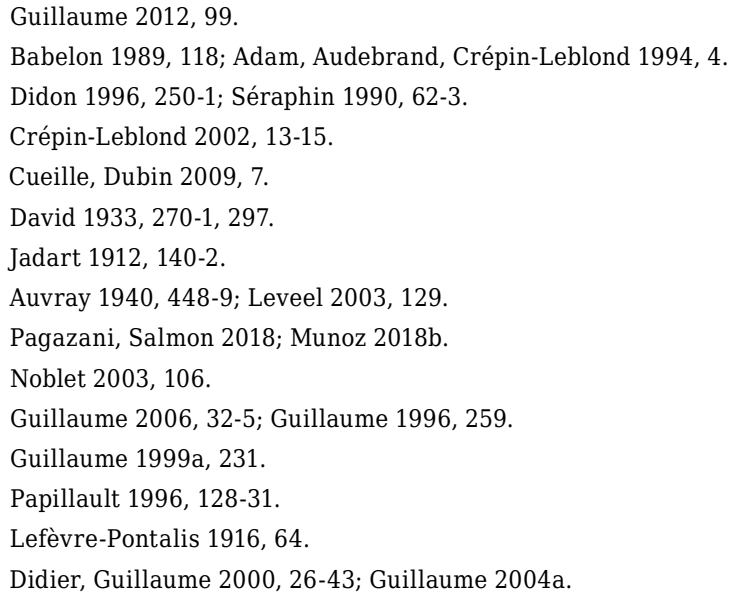




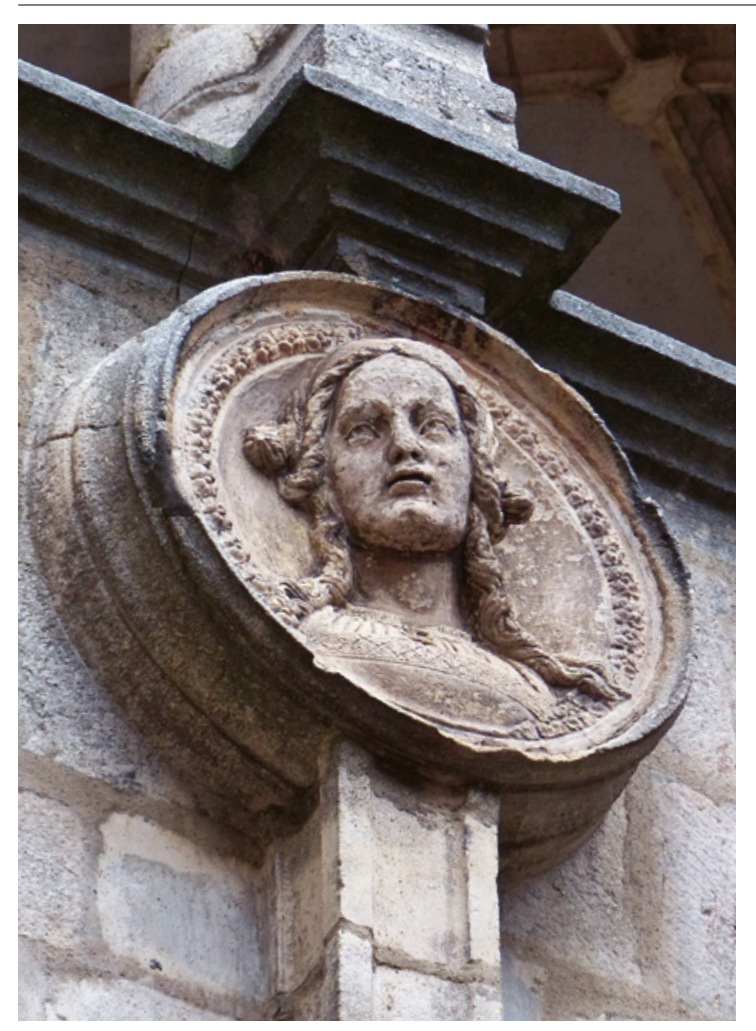

Figure 2 Buste en médaillon. 1522. Pierre. Beaune, cour de l'hôtel Pétral

de la surface, conférait davantage d'animation à l'édifice. Cependant, plus que le témoignage d'un simple attrait pour le rythme rendu par la sculpture décorative, la forme que prirent ces ornements révèle des préférences formelles qui se rapportent à l'évolution de l'histoire du goût à la Renaissance. Ces bustes, qui rendent compte d'une accentuation du relief et de l'illusion de personnages habitant l'architecture, font écho aux nombreuses effigies peintes dans des oculi en trompe-l'œil qui envahissent les voûtes des églises italiennes, à la basilique Santa Croce de Florence ou au baptistère de Sienne, qui trouvèrent leur mise en re- lief dans plusieurs portes en bronze, par exemple dans les portes nord et est du baptistère de Florence réalisées par Lorenzo Ghiberti, puis de façon plus grandiose dans les séries d'ornements en terre cuite vernissée des Della Robbia, notamment à la chartreuse de Galluzzo. Les premiers personnages sculptés répondant à cette typologie dans les monuments français furent ceux en terre cuite de l'hôtel Lallemant de Bourges, vers 1506-1513. ${ }^{28}$ Coupés sous l'encolure, ils correspondent à des visages sortant de médaillons concaves, proches des imagines clipeatae. Dans la même ville, ce type de représentation fut repris en 1515 dans le décor de l'hôtel Cujas, où ces têtes en haut-relief gagnent en prestige par l'emploi du marbre. ${ }^{29}$ Rencontrant le regard des habitants et des visiteurs, ces personnages présentés de face inspirent alors davantage d'interaction que les profils en bas-relief. Ces ornements furent ensuite diffusés le long de la Loire dans les années 1520, dans l'escalier du château de Chenonceaux entre 1513 et $1522^{30}$ et au château de La Verrerie, à Oizon, vers $1520-1525 .{ }^{31}$ Des têtes en haut-relief apparurent également dans diverses provinces françaises durant les mêmes années, par exemple en Bourgogne, dès 1522, à l'hôtel Pétral de Beaune, dont les galeries de la première cour affichent des effigies vues de face, au buste plus ou moins élaboré [fig. 2], au milieu de deux profils, créant une symétrie sur chacun des niveaux. ${ }^{32}$

Néanmoins, l'observation fondée sur les monuments datés montre que les médaillons à têtes et bustes en haut-relief furent beaucoup plus fréquents et plus largement diffusés à partir de la fin des années 1520 et durant les années 1530. Dans le Quercy, le décor de l'archidiaconé Saint-Jean de Cahors, de 1525-1528, est uniquement constitué de bustes vus de face. ${ }^{33}$ De même, de tels ornements furent sculptés à l'hôtel Berthelot de Poitiers vers 1529, ${ }^{34}$ à l'hôtel Bourgtheroulde de Rouen vers $1528-1532^{35}$ et à l'hôtel-de-ville de Beaugency vers 1526-1533. ${ }^{36}$ Des jeux de relief, accentués par le fait que les bustes sont positionnés devant leur encadrement ou superposés à des moulures, s'observent aussi à la maison des Têtes de Valence, de

Ribault 1973

Jongleux 1931, 5-8.

Guillaume 1969.

Ribault 1995, 661-2.

David 1933, 270-1, 297.

Tollon 1993a ; Béa 2008

Fillion 2003.

Gillot, Lettéron 1996, 40-1.

Banchereau 1931; Droguet 2007. 
$1528-1532,{ }^{37}$ et à la chapelle Bouton de Beaune, de 1529-1533. ${ }^{38}$ Des têtes en torsion projetées hors de leur encadrement, qui rappellent les petites effigies en bronze de la célèbre 'porte du Paradis' du baptistère de Florence, créent également davantage de vivacité dans l'architecture, au portail de la chapelle du château de Pagny, construite en 1531-1533, ${ }^{39}$ et dans la cour de l'hôtel de Pins à Toulouse, élevé entre 1528 et $1537 .^{40}$ Ainsi, ces ornements furent développés dans le décor des monuments construits dans les années 1530, dans toutes les provinces françaises. En témoignent par exemple les lucarnes du manoir de Bévillers, à Gonfreville-l'Orcher, construit entre 1528 et $1536,{ }^{41}$ ou la façade de l'église Saint-Pierre de Dreux, terminée entre 1524 et $1541{ }^{42}$ En Normandie, le manoir d'Ango de Varengeville-sur-Mer, élevé entre 1530 et $1541{ }^{43}$ se démarque par des médaillons dans lesquels les personnages sont vus de face et en buste mais sculptés en très bas-relief, comme le montrent aussi les ornements du château de Beauvais, à Vèvres. Au contraire, en Auvergne, ceux en terre cuite de la maison des Consuls de Riom, de 1530-1541, rendent compte d'un attrait pour la proéminence de la figure sur la façade..$^{44}$ Modelés en haut-relief et représentés jusqu'au sternum, leurs visages sortent du sommet du médaillon, comme à l'hôtel Sardini de Paris, aussi en terre cuite.

Plusieurs villes du Sud-Ouest affichent précisément une large diffusion de ces ornements. À Toulouse, l'hôtel de Bernuy comprend un ensemble important de bustes vus de face, intégrés vers 1530 au-dessus du portail et des fenêtres de la tour de la seconde cour. ${ }^{45}$ Par leur insertion dans l'angle saillant de la tour hexagonale, ils contribuent à créer un surcroît de relief, alors que les cadres sont réduits en épousant cet angle. De même, certains personnages du contrefort dit Gramont de la cathédrale Saint-André de Bordeaux, élevé vers 1531-1535, adoptent des poses tortueuses. ${ }^{46}$ Leur proéminence est accentuée par le fait que la tête dépasse légèrement par-dessus la partie supérieure du médaillon, comme cela est aussi visible dans la cour du château d'Assier, où ces ornements furent mis en place vers 1535 et dont les vestiges indiquent que les bustes présentés de face y étaient privilégiés. ${ }^{47}$ Parmi les médaillons provenant de ce château, trois sont attribués à Girolamo Della Robbia, ce dernier ayant ainsi contribué à diffuser cet ornement en France. ${ }^{48}$ Non loin, certaines lucarnes du château de Montal, dont une porte la date 1534, sont enrichies de telles effigies, dont les têtes outrepassent plus largement l'encadrement. ${ }^{49}$ D'autres exemples datés se rencontrent aussi sur l'élévation nord de la chapelle épiscopale de la cathédrale Saint-Pierre de Condom, où le même millésime 1534 est gravé. ${ }^{50}$

Ce goût persista dans les années 1540 dans toute la France, de manière un peu moins intense cependant. Des bustes vus de face dans des médaillons furent ainsi réalisés en 1540 pour la cheminée de l'hôtel Tornié-Barrassy à Toulouse, ${ }^{51}$ pour celle du château de Saint-Blancard, ${ }^{52}$ puis vers 1541 pour l'escalier du château d' Oiron $^{53}$ et pour la maison du Bailliage d'Amiens, ${ }^{54}$ et vers 1540-1544 pour la façade de l'ancienne église Saint-Solenne de Blois. ${ }^{55}$ Élevée vers 1545-1547, la maison des Chevaliers

37 Lacroix 1881

38 David 1929.

39 Journé 2001.

40 Papillault 1996, 135-43; Debuiche 2016, 153.

41 Étienne, Pagazani 2003.

42 Salet 1953.

43 Crépin-Leblond 2005.

44 Renaud 2003.

45 Papillault 1996, 109-24; Debuiche 2012.

46 Roudié 1975, 216-19.

47 Prunet-Tricaud 2014, 112-142; Pagazani 2018.

48 Munoz 2018a.

49 Cueille, Dubin 2009, 6-8.

50 Balagna 2003, 153-4.

51 Munoz 2012, 85; Debuiche 2016, 213.

52 Babelon 1989, 767

53 Crépin-Leblond 2012.

54 La Picardie... 1893-1899, 67.

55 Cospérec 1994, 194-7. 
Figure 3 Buste en médaillon. 1545-1547. Pierre. Viviers, façade de la maison des Chevaliers

de Viviers déploie enfin quatre bustes de grandes dimensions, vus jusque sous le sternum [fig. 3]. ${ }^{56}$ Placés sous les baies du deuxième niveau, ils permettent de noter l'amplification de l'insertion de figures humaines dans l'architecture et la prépondérance de leur emplacement autour des fenêtres.

Si les médaillons étaient d'abord inscrits dans l'ornementation ' à l'antique ' de la Renaissance, l'em-

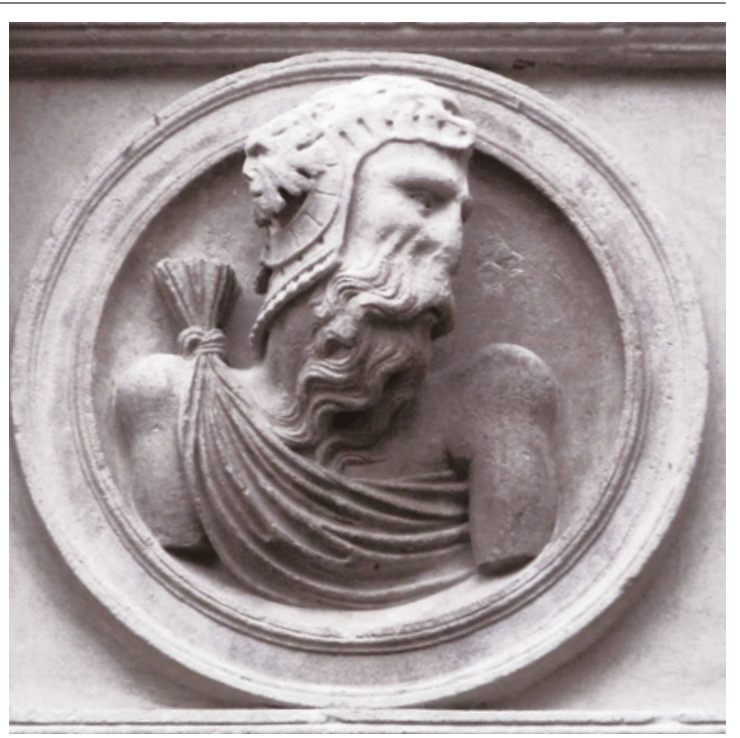

ploi de visages davantage mis en valeur, au sein de champs décoratifs privilégiés, permettait de composer de manière plus manifeste une écriture particulière du mur qui visait à animer les monuments par le relief. Le décor de ces édifices était ainsi doté d'un caractère humain, amplifiant alors la tradition médiévale d'insertion de la figure dans l'architecture.

\section{3 Émergence du buste et affranchissement du cadre}

Certaines effigies prennent davantage d'ampleur sur la façade et témoignent d'une plus grande volonté d'illusion en raison de leur apparition jusqu'à la taille ou avec les bras visibles. La représentation des bras dépend souvent de celle d'objets qui servent à l'identification de ces personnages. À partir des années 1530, le décor sculpté connut ainsi un développement du corps toujours mis en valeur par des médaillons, mais aussi, et de plus en plus, par le biais d'autres encadrements, comme cela pouvait aussi être observé dans le grand cloître de la chartreuse de Pavie.

La première demeure à illustrer ce procédé est probablement l'hôtel parisien de Pierre Le Gendre, du début du XVIe siècle, dont un des vestiges est garni d'un buste d'homme de grandes dimensions, placé dans une coquille au cadre élargi qui laisse entrevoir son riche costume, son collier ainsi que le faucon qu'il tient dans une main. ${ }^{57}$ Ce type de portrait restait cependant rare jusque dans les années 1530. La grande voûte surbaissée taillée vers 15301536 pour la cour de l'hôtel de Bernuy, à Toulouse, affiche ainsi deux chapeaux de triomphe dans lesquels sont sculptés un homme et une femme dont les bras tiennent des phylactères..$^{58}$ De même, l'arc de la façade de la chapelle du château d’Ussé, à Rigny-Ussé, commencée en 1521 et consacrée en 1538, est garni de treize effigies vues presque jusqu'à la taille, dont les bras tiennent des attributs permettant d'identifier le Christ et les apôtres. ${ }^{59}$ Des bustes de dimensions supérieures sont visibles sur le porche de l'église Saint-Michel de Dijon, de

56 Vasselin 2003.

57 Hervier 1977, 48.

58 Papillault 1996, 109-24; Debuiche 2012.

59 Guillaume, Lamirault-Sorin 2003. 


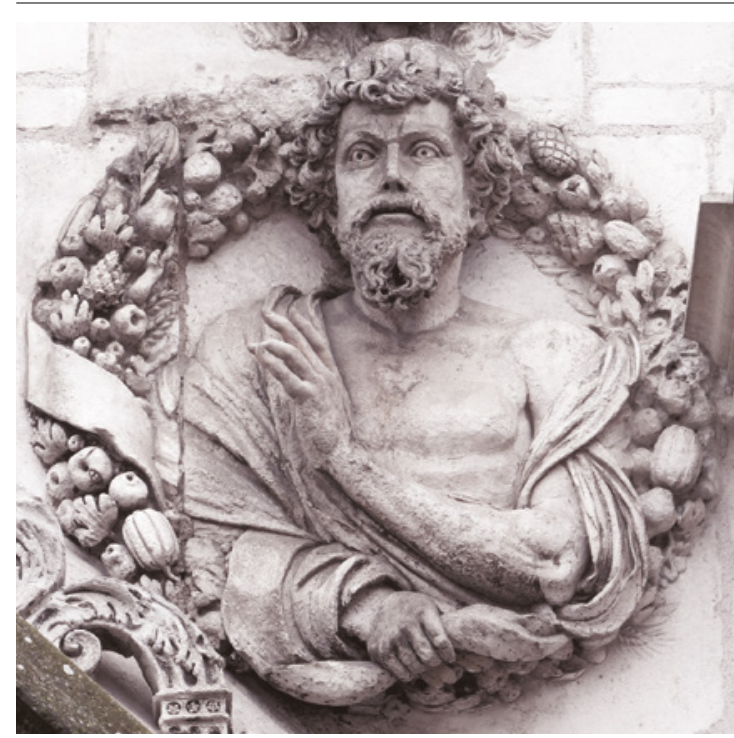

Figure 4 Buste d'Ézéchiel. 1537. Pierre. Dijon, porche de l'église Saint-Michel

1537, où six portraits prennent place dans des couronnes. ${ }^{60}$ Certains d'entre eux ne tiennent aucun objet, ce qui tend à indiquer un goût pour l'émergence de la figure, sans que la présence des bras n'ait toujours d'utilité définie [fig. 4].

Par ailleurs, le développement formel de la figure humaine peut être intimement lié aux encadrements dont le traitement parfois exceptionnel contribue à faire ressortir des effigies taillées en très haut-relief sur l'élévation. L'ensemble mis en scène dans les façades sur cour du château de Montal, daté de 1527, expose ainsi les portraits de la propriétaire Jeanne de Balsac et de sa famille, représentés à la manière de bustes privés à l'italienne et placés devant des médaillons. ${ }^{61}$ Ces encadrements semblent alors davantage destinés à les désigner, par leur mise en valeur et par l'indication de leurs noms, qu'à les contenir sur la surface du mur [fig. 5]. D'une autre manière encore, les prophètes présents sur la façade de la collégiale Saint-Jean-Baptiste de Montrésor, de 15321541, montrent un relief accentué par le creusement de champs concaves qui n'ont plus fonction d'encadrement. $^{62}$

Une plus grande mise en valeur des bustes vus

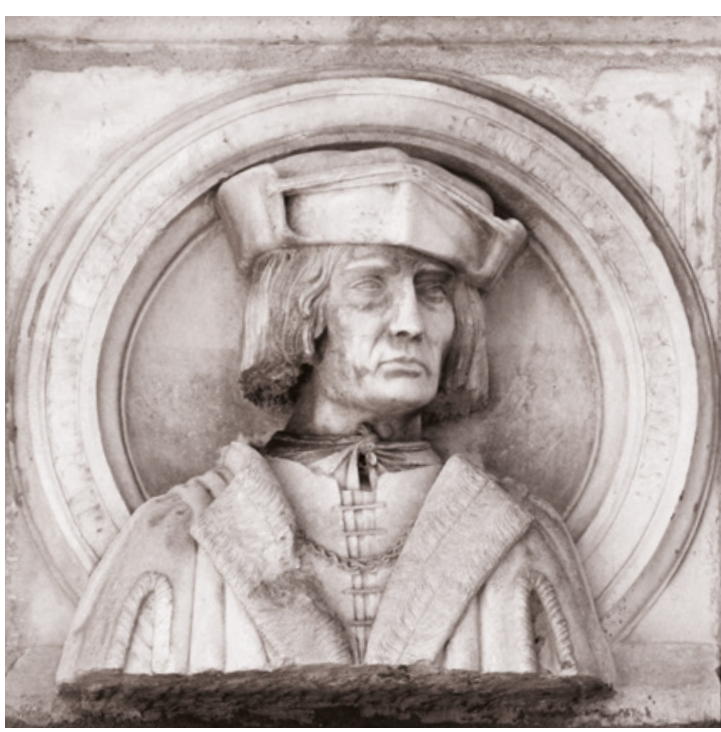

Figure 5 Buste de Robert de Balsac. 1527. Pierre. Saint-Jean-Lespinasse, cour du château de Montal

de face dans l'architecture s'opère à travers des encadrements autres que les médaillons, l'effigie pouvant alors occuper davantage d'espace. Surtout situés autour des baies et dans les entablements, ces reliefs témoignent d'une place toujours plus importante de la figure dans le décor, révélant des enjeux liés à l'interaction suscitée entre portrait et observateur. Ces personnages étaient cependant toujours inspirés de l'Antiquité, notamment des stèles funéraires romaines, lesquelles étaient fréquemment décorées de bustes sans encadrement circulaire, parfois placés dans de grandes niches rectangulaires.

Les frontons qui couronnent les portes, les fenêtres et les lucarnes constituaient des cadres privilégiés pour accueillir de tels portraits. Comme les précédents ornements, cette typologie trouvait ses modèles dans l'art italien, notamment au Castelnuovo de Naples. Par l'examen de cet élément en tant que champ décoratif, Jean Guillaume a justement rendu compte de l'attrait pour la richesse ornementale qui le caractérisait en France, plus qu'en Italie ${ }^{63}$ Les premiers frontons ayant reçu de tels reliefs garnissent par exemple le haut de la porte du manoir de La Possonnière, à Couture-sur-Loir, re- 
manié vers $1515,{ }^{64}$ le couronnement des lucarnes de l'aile François I ${ }^{\text {er }}$ du château de Blois, de 1515$1524,{ }^{65}$ et celui d'une lucarne conservée au Victoria \& Albert Museum de Londres, provenant du château de Chambord, dont la construction décidée en 1516 par François Ier fut commencée en 1519 et interrompue en 1525-1526. ${ }^{66}$ Cet élément indique, comme les précédents, que les frontons réalisés entre 1515 et 1525 étaient le plus souvent surhaussés, selon des proportions qui renvoyaient au goût pour la verticalité héritée de l'architecture gothique. Leurs tympans faisaient ainsi valoir des formes favorables à l'accueil du buste, la coupe horizontale de ce dernier pouvant être posée sur la base et la tête pouvant être inscrite dans le sommet.

Par la suite, à partir de 1525 environ et dans les années 1530, les monuments bénéficièrent d'une plus grande variété de frontons dans lesquels les effigies pouvaient être plus ou moins développées. Des figures à mi-corps garnissent dans les frontons curvilignes des lucarnes au château des Granges-Cathus, élevé vers $1525,{ }^{67}$ et au château de Villesavin, à Tour-en-Sologne, construit de 1526 à $1537 .{ }^{68}$ Ce dernier montre plusieurs lucarnes, portant parfois la date de 1537, qui affichent des personnages féminins vus jusqu'à la taille représentant les Muses. Leur vue à mi-corps et les actions qu'elles exécutent évoquent ainsi une présence humaine au-dessus des ouvertures, témoignant d'une place plus importante accordée à la figure et à l'animation que cette dernière procure à l'architecture. D'autres bustes inscrits dans des frontons trapézoïdaux et semi-circulaires se trouvent aussi à l'hôtel Chabouillé de Moret-surLoing, de 1527 environ, ${ }^{69}$ au château de Puyguilhem à Villars, de $1525-1530,{ }^{70}$ ou encore au château de Fontaine-Henry, vers 1537-1544. ${ }^{71}$ Enfin, l'hôtel d'Escoville à Caen, construit entre 1534 et $1540,{ }^{72}$ laisse voir un attrait important pour le développement et la mise en scène de la figure humaine. Des hommes et des femmes vus à mi-corps et superposés sont sculptés dans divers encadre- ments et sont représentés en train de jouer d'un instrument ou accoudés aux allèges.

Plusieurs monuments élevés à partir des années 1540 témoignent quant à eux d'un goût pour les frontons de diverses formes surbaissés, lesquels permettent de mettre en valeur des bustes outrepassant parfois largement leur sommet. Si cela peut être observé sur le pavillon est du château de Gramont, réalisé entre 1530 et $1545,^{73}$ ce procédé est plus richement décliné sur la façade sur cour de l'aile nord du château de Bournazel, qui fut élevée en 1545 avant que l'aile est ne soit construite. ${ }^{74}$ L'entrée ainsi que toutes les baies des deux premiers niveaux sont ainsi surmontées d'un fronton triangulaire ou parfois semi-circulaire surbaissé, alors que les lucarnes du troisième niveau sont couronnées de frontons trapézoïdaux, chacun de ces cadres étant pourvu d'un buste en haut-relief. Non loin, ce dernier type de fronton se retrouve pour deux lucarnes du château de Graves à Villefranche-de-Rouergue, construit entre 1543 et $1555,{ }^{75}$ où l'affirmation de la figure, plus appuyée encore, se traduit par la représentation d'un homme et d'une femme à mi-corps dont les bras sont apparents [fig. 6].

Des effigies sculptées en haut-relief pouvaient aussi être insérées dans d'autres types d'encadrements qui contribuaient à les mettre en valeur. Un principe original consiste par exemple à enrichir le décor des frises doriques de bustes prenant la place des métopes entre deux triglyphes. La façade de l'hôtel de La Salle à Reims, sur laquelle est gravée la date de 1545, expose un premier niveau scandé de pilastres doriques surmonté d'un second à pilastres ioniques. Créant un rythme régulier sur la partie gauche de la façade, les métopes de la frise du premier niveau sont ainsi garnies de patères, d'écus et d'effigies d'hommes et de femmes vêtus ' à l'antique ' taillées en haut-relief. Le portail de la chapelle des fonts baptismaux de l'église de Semur-en-Auxois, caractérisé par une superposition des ordres dorique, ionique et corinthien, affiche le même procédé mais de façon accentuée, toutes les métopes de la frise du
70 Guillaume 1999b, 281, 288, 291.

71 Faisant 2010, 62-4

72 Faisant 2013, I, 430-1.

73 Dubin, Rebière 2011, 7-8; Tollon 2014.

74 Verdier 2012, 14-19.

75 Crépin-Leblond 2011. 


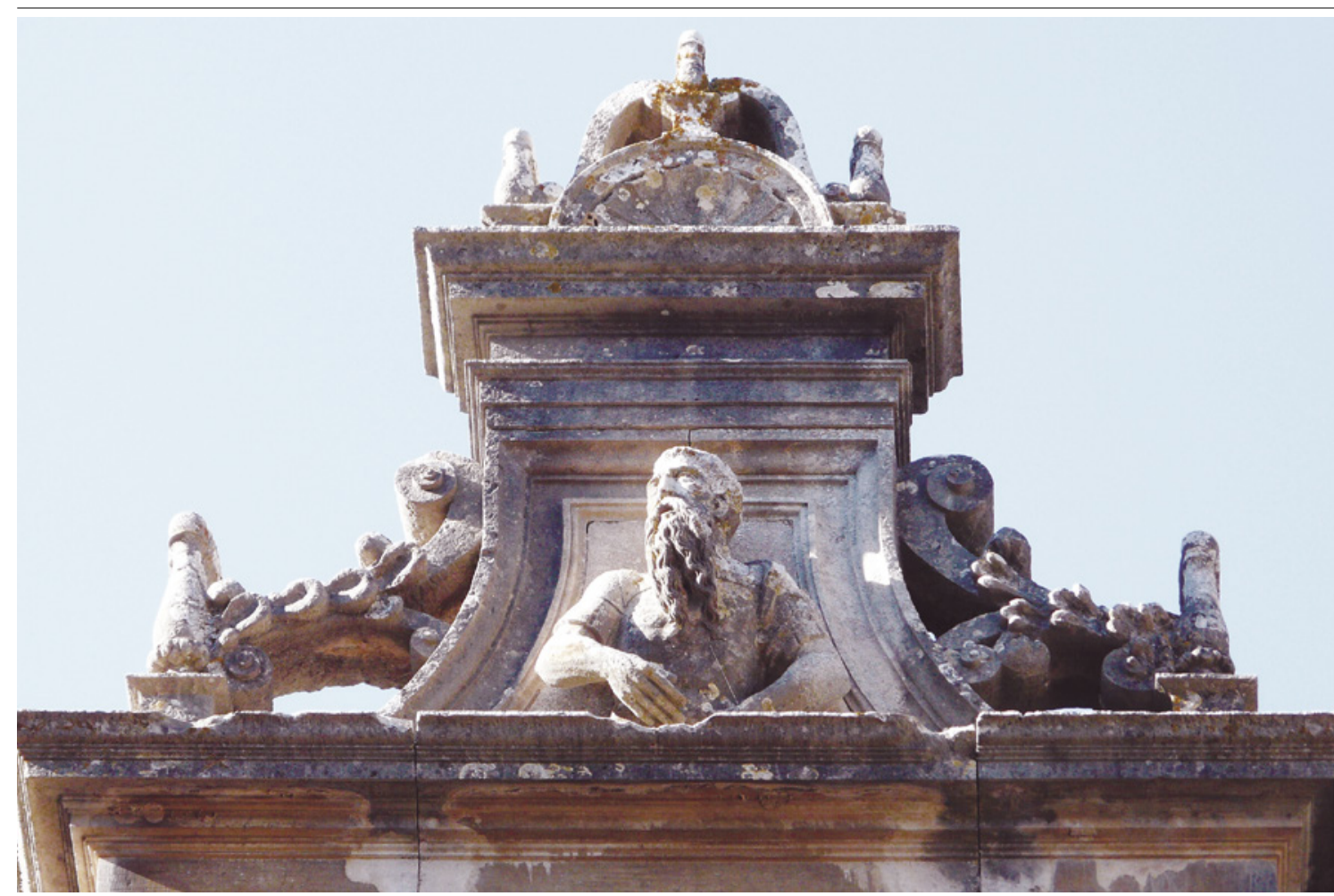

Figure 6 Sommet d'une lucarne. 1543-1555. Pierre. Villefranche-de-Rouergue, château de Graves

premier niveau étant enrichies de bustes en haut-relief. ${ }^{76}$ Dans la même église, le goût pour l'introduction de telles figures dans les frises s'observe aussi sur le portail de la chapelle sud, où trois personnages décorent les ressauts de l'entablement.

À la suite des médaillons qui révélaient déjà un goût de plus en plus prégnant pour le relief des visages, l'attrait pour des bustes émergents domina dans les années 1540. Cette décennie a précisément été perçue comme une période de transition dans plusieurs domaines artistiques en Europe, durant laquelle un rapport nouveau entre la sculpture et l'architecture fut notamment illustré par la personnalité de Jean Goujon..$^{77}$ Insérées dans différents types d'encadrements qui les mettaient en valeur d'une autre manière et qui disparaissaient parfois derrière elles, ces effigies révèlent ainsi un plus grand intérêt pour la représentation du corps et pour l'interaction entre architecture et sculpture.

\section{Affirmation du corps dans le décor : jeux d'illusion et théâtralité}

Plusieurs monuments révèlent une place significative accordée au corps sculpté, ce dernier acquérant un rôle plus déterminant encore que les ornements observés précédemment. Ces personnages en haut-relief, le plus souvent représentés à mi-corps, sont totalement dépourvus d'encadrement ou sont placés dans de fausses fenêtres. Fei- gnant une présence humaine, voire une activité, ils soulèvent alors des questions quant à leur iconographie.

Les médaillons eux-mêmes pouvaient témoigner de jeux d'illusion. Cela s'observe notamment à l'hôtel d'Escoville de Caen, construit entre 1534 et $1540,{ }^{78}$ où deux hommes barbus sont représen- 


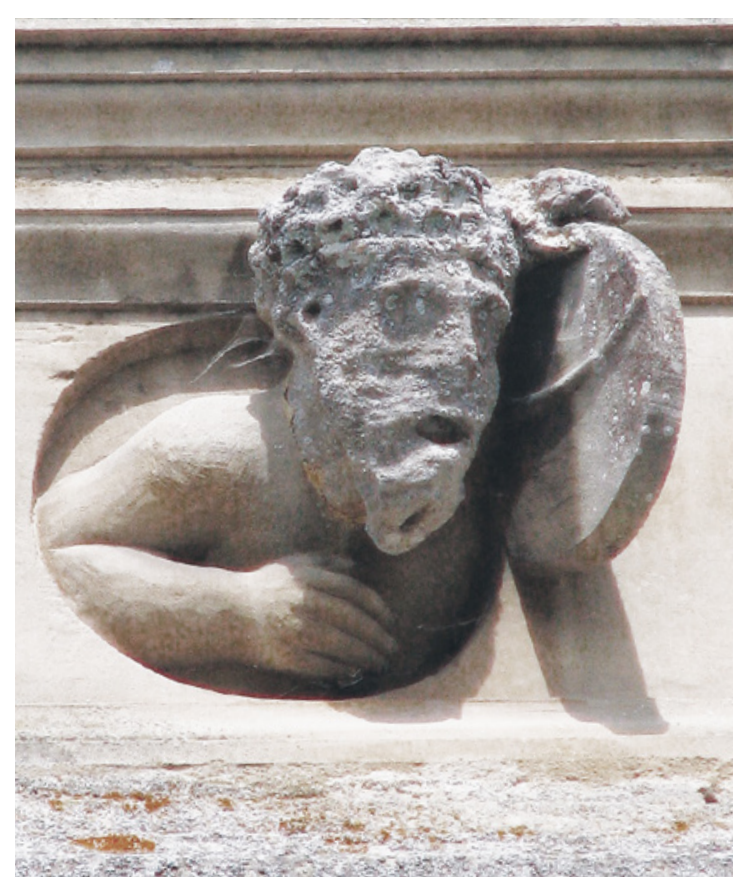

Figure 7 Détail d'une lucarne. 1537. Pierre. Château de Fontaine-Henry. Wikimedia Commons

tés surgissant de médaillons sculptés sur l'entablement du second niveau et passant les bras par des oculi creusés sous cet entablement pour tenir les chutes d'ornements qui rythment la façade. Un jeu d'illusion qui imite une activité humaine caractérise également une lucarne du château de Fontaine-Henry, reconstruit à partir de 1515 environ, puis vers $1537-1544 .{ }^{79}$ Celle-ci, qui porte la date 1537, est ornée d'un buste d'homme représenté en train d" ouvrir ' l'oculus par lequel il surgit [fig. 7].

L'affirmation de la figure humaine dans l'architecture prend une plus grande intensité dans la réalisation de personnages en haut-relief totalement dépourvus d'encadrement. Usant de variations qui vont de têtes et bustes aux dimensions relativement réduites jusqu'à des effigies vues à mi-corps, ces hommes et femmes adoptent parfois des positions particulières et confèrent encore davantage d'animation aux élévations en simulant une présence, en même temps qu'ils révèlent de façon plus vive l'interaction fondamentale entre sculpture et architecture à la Renaissance. Des bustes sans encadrement mais tout d'abord peu développés enrichissent ainsi plusieurs monuments datés des années 1520-1530, dans diverses provinces françaises. Deux furent par exemple réalisés pour la porte de l'hôtel Berthelot de Poitiers, en 1529. ${ }^{80}$ De même, à Troyes, à l'hôtel de Marisy, construit de 1528 à 1531, cinq bustes agrémentent la partie inférieure d'une échauguette. ${ }^{81}$ Au château de Chailly, qui fut remanié entre 1525 et 1534 pour Hugues de Loges, grand bailli d'Autun, puis entre 1544 et 1550 pour son fils Louis II, les écoinçons de l'arc du deuxième niveau de la façade sont aussi décorés d'effigies dépourvues d'encadrement. ${ }^{82}$

À partir de la fin des années 1530, ces personnages prirent des formes beaucoup plus amples, avec parfois des bras représentés sans avoir pour fonction de tenir des attributs mais dans l'unique but d'accentuer l'expressivité et l'animation créées. Ainsi en témoigne, près de Troyes, le portail méridional de l'église Saint-Loup-de-Sens d'Auxon, daté de $1537 .{ }^{83}$ Celui-ci met en évidence des figures placées dans des frontons et des apôtres taillés dans des cadres formés par la succession de colonnettes rythmant l'entablement, mais aussi deux autres bustes logés dans les écoinçons, plus grands encore. Un large ensemble d'effigies en haut-relief fut également sculpté en frise, sans encadrement, au sommet de la tour sud de la cathédrale Saint-Gatien de Tours, qui fut achevée vers 1534-1547. ${ }^{84}$

Cet attrait pour une stricte affirmation de la figure humaine est abondamment perceptible dans le Midi toulousain et, non loin, autour de Rodez. À Villefranche-de-Rouergue, la maison Dardenne, remaniée vers 1543, met ainsi l'Antiquité à l'honneur à travers douze bustes de femmes et d'hommes répartis sur les allèges des trois galeries et balcons sur cour [fig. 8]. ${ }^{85}$

En 1544, l'élévation de la tour de l'hôtel de Brucelles, à Toulouse, fut l'occasion de développer, au-dessus de chaque ouverture, sept personnages surgissant à mi-corps et proches de la ronde bosse [fig. 9]. ${ }^{86}$ Dans la même ville, les bustes disposés en

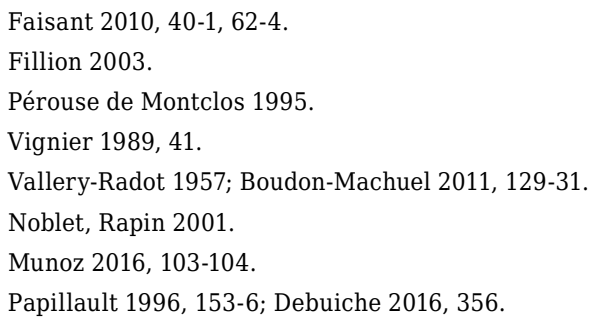


Sarah Munoz

Des figures hors cadre. L'émergence du corps sculpté dans l'architecture de la Renaissance en France

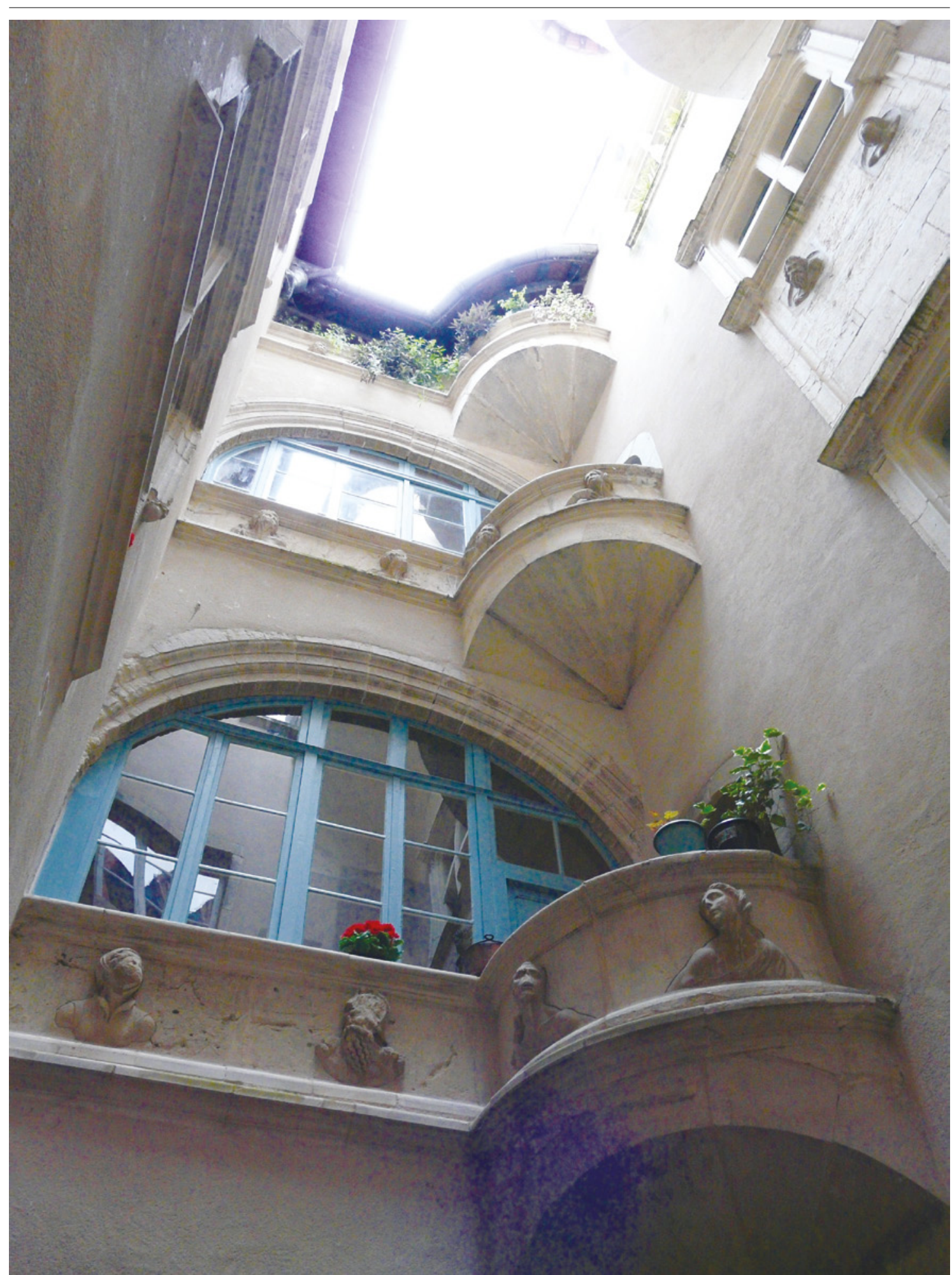

Figure 8 Vue d'ensemble de la cour. Vers 1543. Villefranche-de-Rouergue, maison Dardenne 


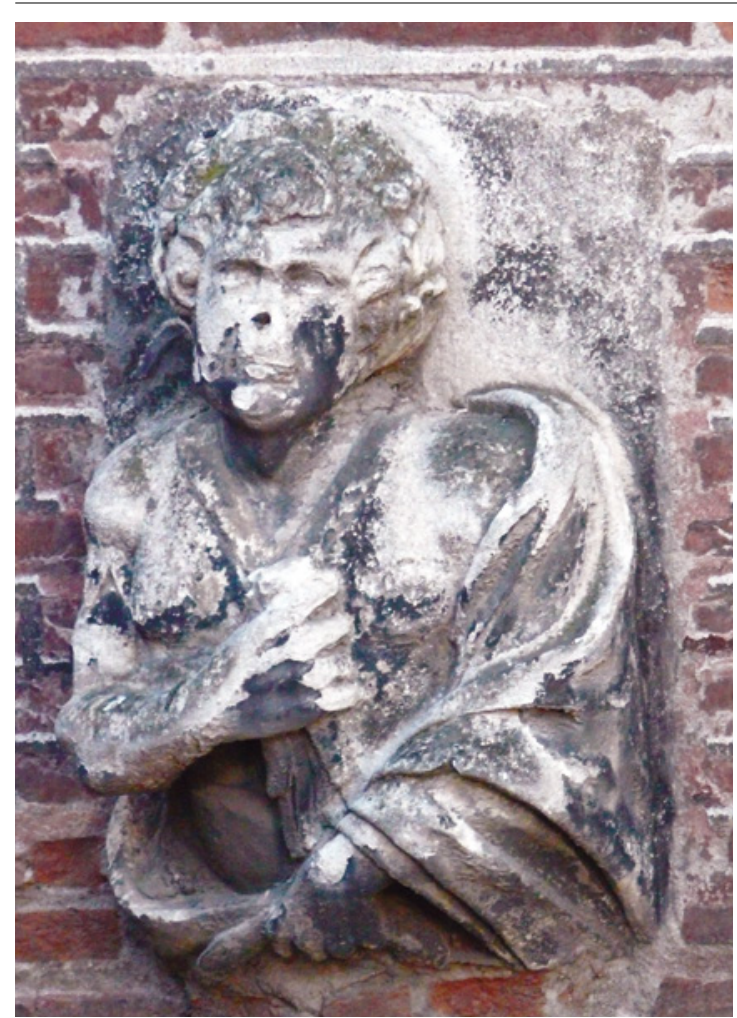

Figure 9 Buste du cinquième niveau. 1544. Pierre. Toulouse, tour de l'hôtel de Brucelles

frise qui décoraient l'ancien clocher de l'église de la Dalbade, taillés entre 1547 et 1556, montraient un vaste ensemble de personnages saillants, dépourvus de cadre, représentant des personnages bibliques. ${ }^{87}$ Plus à l'est, à Caunes-Minervois, si la galerie de la première cour de l'hôtel d'Alibert porte cinq bustes en médaillon précisément datés par une inscription de 1552, la seconde cour affiche quant à elle deux bustes jaillissant de la pierre sur l'allège d'une autre galerie, cette partie de l'édifice correspondant à la date de 1560, présente sur le puits. ${ }^{88}$ La récurrence de ce type de représentation, observée dans le Sud-Ouest de la France entre 1540 et 1560, pourrait ainsi permettre de proposer une datation large pour les effigies présentant une mise en scène relativement proche, dans la cour de la maison Jeanne de Lartigue, à Bordeaux, dont les circonstances de construction sont inconnues. ${ }^{89}$

Enfin, dénotant une mise en scène amplifiée de la figure humaine sur les élévations, d'autres effigies étaient insérées à l'intérieur de baies feintes dont les modèles se trouvent quant à eux dans l'art gothique français et surtout flamand ou germanique. ${ }^{90}$ En France, le palais Jacques Cœur de Bourges fut ainsi le premier à jouer avec ces spectaculaires effets d'illusion, entre 1443 et $1451 .{ }^{91} \mathrm{La}$ façade sur rue est ornée de deux fausses fenêtres, aux allèges desquelles sont accoudés un homme et une femme, dont les bustes ont été inversés lors des restaurations du XIXe siècle, et placés de part et d'autre d'une grande niche qui contenait le portrait équestre de Charles VII. ${ }^{92}$ Les effets créés sur la façade par la réalisation de fausses fenêtres s'inscrivent ainsi dans le goût pour les jeux d'illusion, appréciés et diffusés à la Renaissance depuis le célèbre oculus peint par Mantegna dans la Chambre des Époux du Palais ducal de Mantoue ou la mouche de Giotto rendue fameuse par Vasari. ${ }^{93}$ Comme ces trompe-l'œil peints, les bustes placés dans des baies feintes sculptées donnaient une nouvelle dimension à l'imitation de la nature. Au XVIe siècle, l'érudit florentin Vincenzo Borghini, dans sa Selva di notizie, qui questionnait la supériorité des arts, comparait ainsi le pouvoir du relief, propre à la sculpture, à celui de la couleur, relative à la peinture, lorsqu'il s'agissait de créer des jeux d'illusion. ${ }^{94}$

Le thème décoratif des fausses fenêtres fut repris dans plusieurs demeures du XVIe siècle, principalement dans les années 1530-1550, afin d'attirer l'attention sur certains personnages. La présence simulée de ces derniers trouve un écho dans le fait qu'ils sont généralement placés autour des ouvertures. Vers 1525-1528, deux fausses fenêtres richement ornées furent ainsi sculptées sur la façade de la maison Jaillet de Paray-le-Monial. ${ }^{95}$ Placés directement au-dessus du premier niveau, un homme et une femme y apparaissent vêtus d'habits du XVIe siècle. Ils se tournent l'un vers l'autre et le personnage féminin tient une fleur

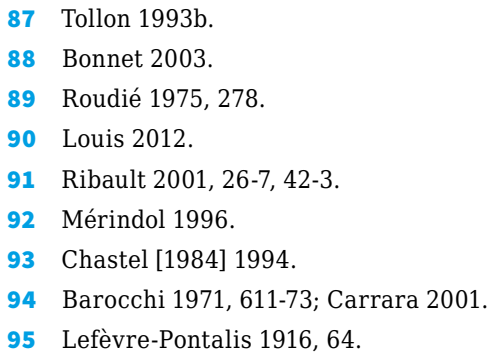


Sarah Munoz

Des figures hors cadre. L'émergence du corps sculpté dans l'architecture de la Renaissance en France

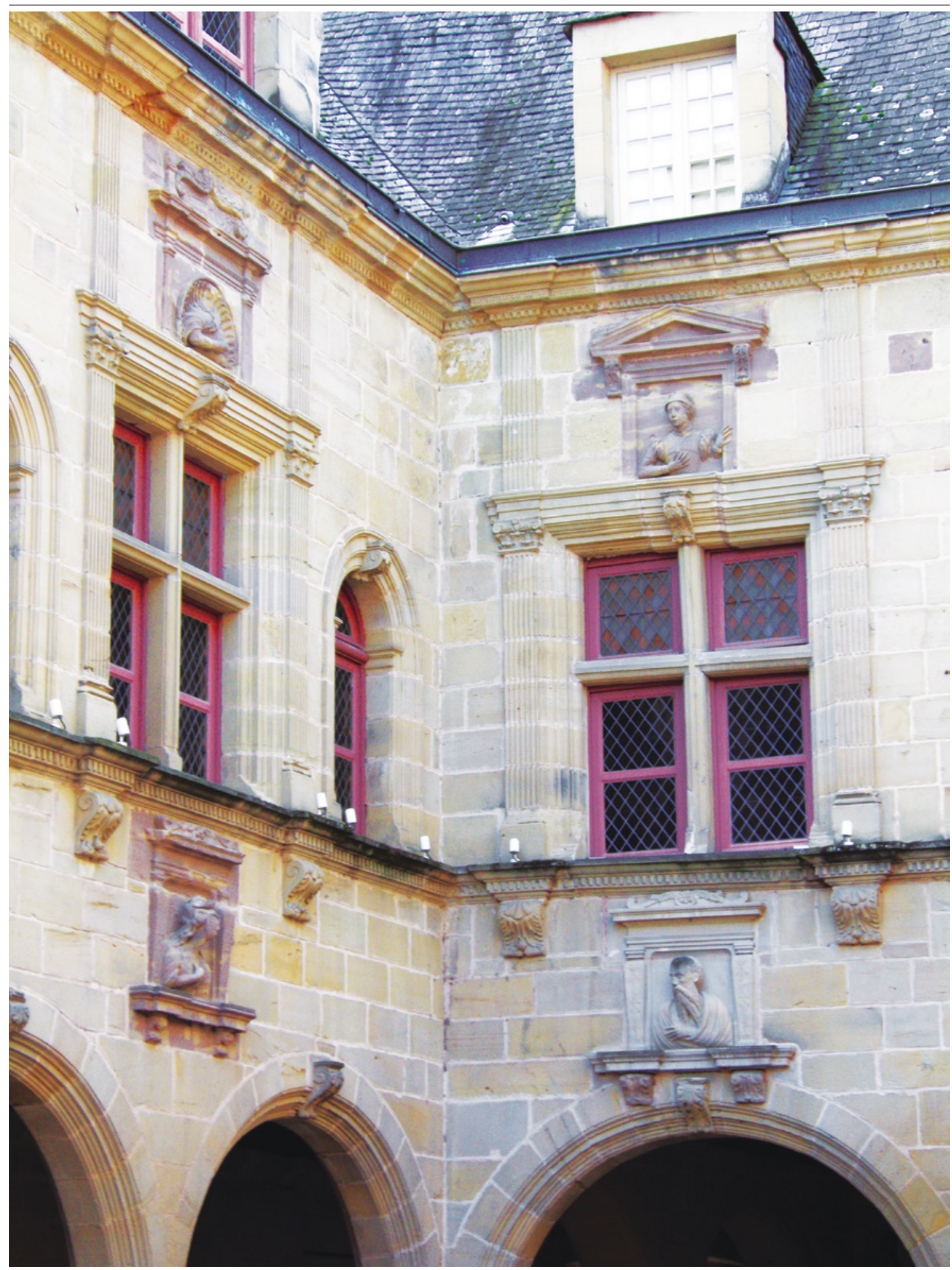

Figure 10 Vue de deux travées de la cour. 1548-1560. Brive-la-Gaillarde, hôtel Labenche 
dans sa main. Une ornementation proche caractérise le portail de la maison dite du marquis de Pontevès, à Barjols, sur lequel est inscrite la date de 1532. Une même mise en scène est opérée, les corps étant tournés l'un vers l'autre, tandis que la femme porte une main sur sa poitrine et arbore une corne d'abondance de l'autre et que l'homme tient un bâton de commandement et une fleur. Vers 1539-1541, l'élévation sud de l'église Notre-Damedes-Marais, à La Ferté-Bernard, fut aussi garnie de baies feintes dans lesquelles sont présentés Jules César et Cléopâtre ${ }^{96}$ Ce principe fut magnifié, dans une sculpture maladroite cependant, entre 1548 et 1560, à l'hôtel Labenche de Brive, où chaque travée des deux façades sur cour affiche une alternance de baies réelles et de fausses fenêtres d'où se penchent des bustes de femmes et d'hommes en très haut-relief [fig. 10]. ${ }^{97}$ Des présences feintes pouvaient aussi être retranscrites dans des cadres rectangulaires évoquant de simples ouvertures, à

\section{Conclusion}

Tous les types de portraits, à savoir les profils en bas-relief mis en valeur par un cadre, les têtes présentées de trois quarts ou de face en haut-relief et les bustes vus à mi-corps, bien que différents, peuvent être rapprochés dans un même ensemble. La similarité des champs décoratifs qu'ils enrichissent et leurs fonctions communes d'accueil, d'animation et d'humanisation du décor indiquent en effet qu'ils découlent les uns des autres et qu'ils furent tous réalisés selon une même volonté antiquisante.

L'examen précis de ces différents ornements, fondé sur les monuments les mieux datés, rend compte de leur métamorphose depuis leur introduction au début du XVIe siècle jusqu'à leur quasi disparition vers 1550 . D'une manière générale, il apparaît ainsi que les visages vus de profil, qui marquèrent l'apparition de cet ornement, furent surtout diffusés jusque dans les premières années de la décennie 1530. Les têtes et bustes présentés de face dans des médaillons furent quant à eux plus largement appréciés entre 1520 et 1540 . Enfin, les personnages dépourvus de cadre ou placés dans de fausses fe- l'instar de ceux taillés dans les années 1530-1550,98 dans la cour de l'hôtel Guimoneau à Riom, desquels surgissent un homme et une femme, ou de ceux qui surmontent le portail de la chapelle de l'ossuaire Saint-Salomon à La Martyre. Datée de 1619, cette chapelle témoigne tout particulièrement des survivances tardives de l'ornementation Renaissance en Bretagne. ${ }^{99}$

Par l'image récurrente de couples vêtus d'habits du XVIe siècle, ces bustes, placés au regard de tous sur les façades ou de façon ostentatoire dans les cours des demeures privées, invitent à penser qu'il pourrait s'agir de représentations de propriétaires qui ne seraient pas toujours sculptés de façon réaliste mais le plus souvent de façon illusoire et allusive. Situés dans les mêmes champs décoratifs que les médaillons, ces corps sculptés émergeant de la surface du mur provoquaient une accentuation et une vivacité du relief qui induisaient de nouveaux rapports entre structure et sculpture décorative.

nêtres, parfois proches de la ronde bosse et vus jusqu'à la taille, se développèrent surtout dans les années 1540 et 1550. Ces transformations formelles révèlent ainsi un goût de plus en plus prononcé pour le relief, pour l'émergence du corps et pour la mise en scène d'une figure humaine vivifiée dans l'architecture. Ces métamorphoses changent alors l'interaction entre l'élévation et son décor. Accueil et animation sont renforcés par l'affirmation et le développement des effigies. Un siècle plus tard, ces procédés d'enrichissement résonnèrent dans la conférence sur L'union de l'art avec la nature prononcée le 4 juillet 1671 par le sculpteur Michel Anguier à l'Académie royale de peinture et de sculpture. Ce dernier conseillait de représenter « des personnes qui seraient venues du dedans du palais pour se faire voir sur les balcons ou par les fenêtres ${ }^{100}$ La mise en relief progressive du corps sculpté sur la surface du mur trouvait ainsi un prolongement dans les prescriptions de l'un des plus importants sculpteurs du XVIIe siècle, qui affirmait la nécessité de créer des jeux d'illusion par l'humanisation de l'architecture.

96 Pflieger 2015, 33-57.

97 Corvisier 2007.

98 Thiéry 1935.

99 Rioult 2009; Duhem 2012, 53.

100 Lichtenstein, Michel 2006, 418-19. 


\section{Appendices}

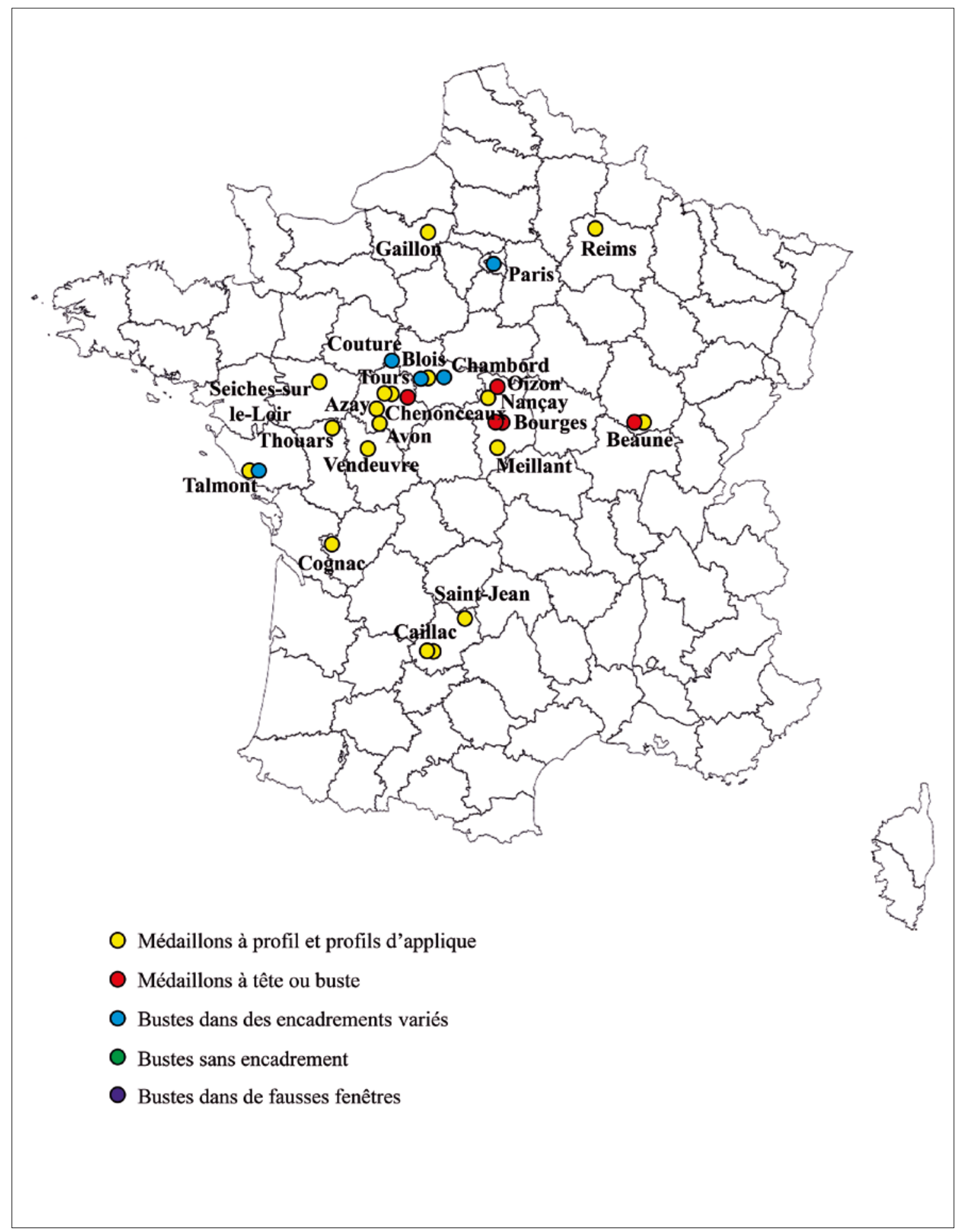

Carte 1 Localisation des médaillons et bustes sculptés entre 1500 et 1525 


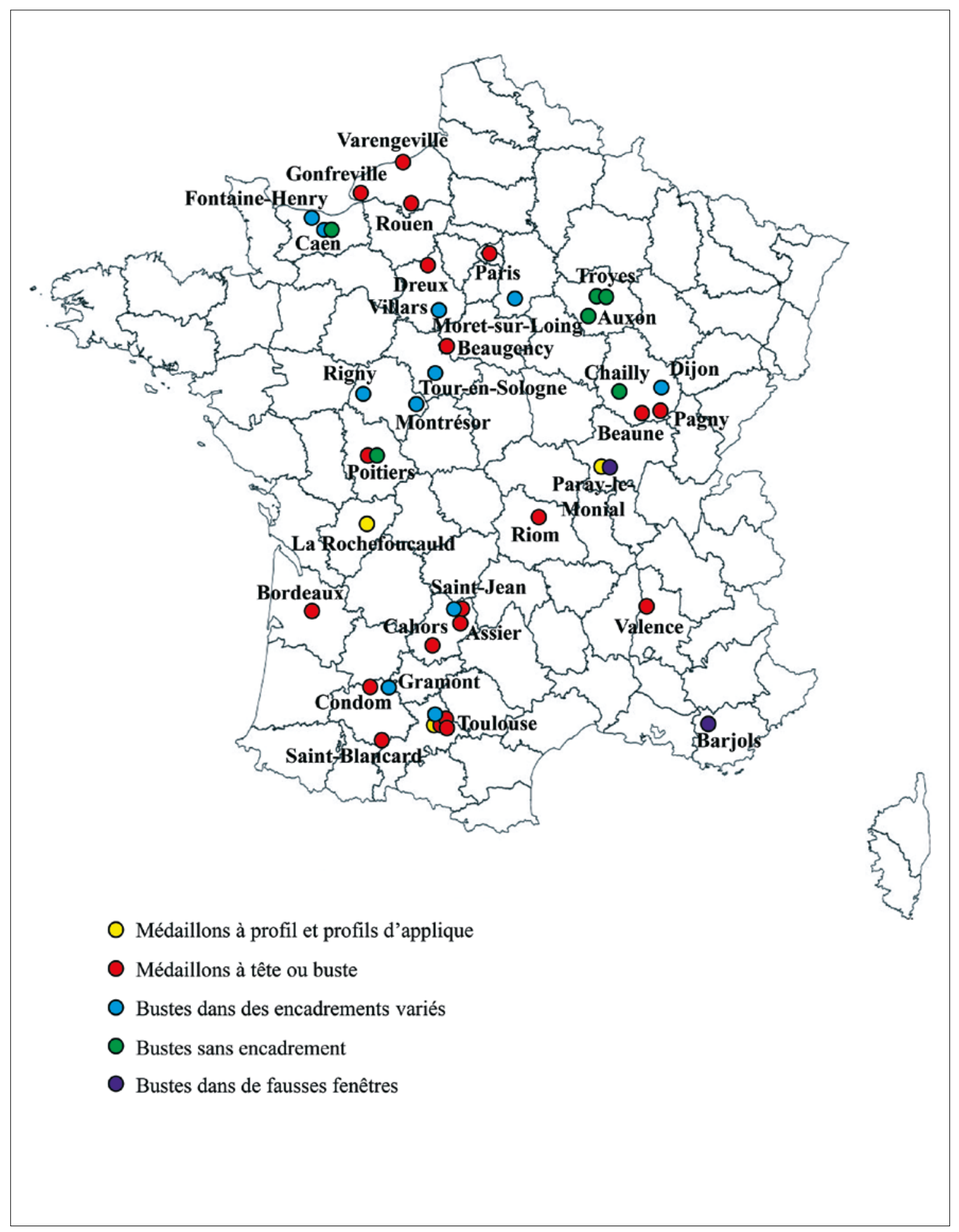

Carte 2 Localisation des médaillons et bustes sculptés entre 1525 et 1540 


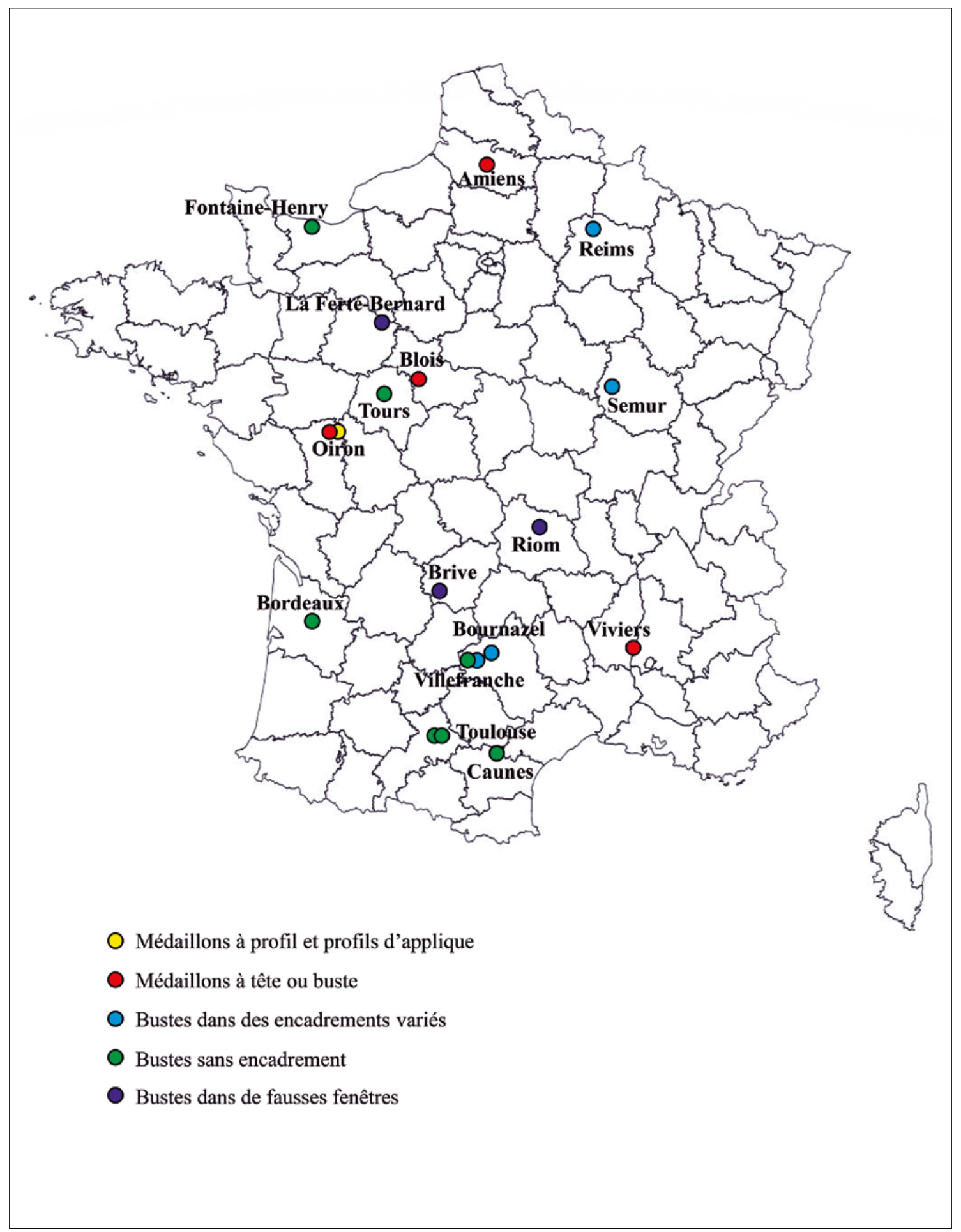

Carte 3 Localisation des médaillons et bustes sculptés entre 1540 et 1560 


\section{Sources}

Fulvio, A. (1517). Illustrium imperatorum et illustrium virorum aut mulierum vultus ex antiquis numismatibus expressi emendatum correptumque opus per Andream Fuvium diligentissimum antiquarium. Rome.

Huttich, J. (1525). Imperatorum Romanorum libellus: Una cum imaginibus, ad vivam effigiem expressis. Strasbourg.

\section{Bibliographie}

Adam, C. ; Audebrand, F. ; Crépin-Leblond, T. (1994). Les châteaux de François $I^{\text {er }}$. Écouen.

Auvray, H. (1940). « L'hôtel de la Société archéologique ou Babou de La Bourdaisière ou du Dauphin ». Bulletin de la Société archéologique de Touraine, 27, 441-79.

Babelon, J.-P. (1989). Châteaux de France au siècle de la Renaissance. Paris.

Balagna, C. (2003). "L'apparition des formes de la Renaissance dans l'architecture religieuse de la Gascogne centrale ». Esquieu, Y. (éd.), Du gothique à la Renaissance. I-Architecture et décor en France $(1470-1550)=$ Conference Proceedings (Viviers, 20-23 September 2001). Aix-en-Provence, 145-62.

Banchereau, J. (1931). « Hôtel de ville ». Congrès archéologique de France, 93, 355-8.

Barocchi, P. (a cura di) (1971). Scritti d'arte del Cinquecento. Milano.

Béa, A. (2008). «Dendrochronologie en Midi-Pyrénées. Bilan du programme 2004-2008». Mémoires de la Société archéologique du Midi de la France, 68, 171-205.

Beck, B. (2003). «Les monuments civils de la Renaissance caennaise ». Beck, B. ; Bouet, P. ; Étienne, C. Lettéron, I. (éds), L'architecture de la Renaissance en Normandie = Conference Proceedings (Cerisy-la-Salle, 30 September-4 October 1998), vol. 2. Condé-surNoireau ; Caen, 139-52.

Bedocchi Melucci, A. (1988). «I ritratti all'antica nei portali genovesi del XV e XVI secolo ». Rivista di archeologia, 11, 63-88.

Bonnet, J.-L. (2003). « Jehan d'Alibert, abbé et seigneur de Causne ». Histoire et généalogie en Minervois, 53, 16-25.

Boudon-Machuel, M. (2011). Un foyer artistique au temps des guerres de Religion, la sculpture religieuse en Champagne méridionale (1530-1600), habilitation à diriger des recherches en histoire de l'art. Tours.

Boudon-Machuel, M. ; Julien, P. (2015). «Autour de Jean Goujon. Ambitions et inflexions de la sculpture française, royale et provinciale ». Baumer, L.E.; Elsig, F. ; Frommel, S. (éds), Les années 1540: regards croisés sur les arts et les lettres = Conference Proceedings (Genève, 11-12 avril 2011). Berne, 187-216.

Bray, A. (1958). "Le retour à Moret de la 'Maison de François I ${ }^{\mathrm{er}}$ '》. Les monuments historiques de la France, 4, 42-6.

Bresc-Bautier, G. (2007). « Les médaillons de marbre provenant du château de Gaillon, début du XVle siècle ». Bulletin de la Société nationale des antiquaires de France, 160-78.
Martin, J. (1547). Architecture ou Art de bien bastir, de Marc Vitruve Pollion Autheur Romain antique: mis de Latin en Francoys, par lan Martin Secretaire de Monseigneur le Cardinal de Lenoncourt. Paris.

Bresc-Bautier, G. (2010). « Médailles et profils d'applique en marbre ". Le château de Gaillon, fastes de la Renaissance en Normandie $=$ Exhibition Catalogue (Rouen, 27 February-12 May 2008). Rouen, 13-27.

Burnett, A. ; Schofield, R. (1997). "The Medallions of the Basamento of the Certosa di Pavia. Sources and Influence ». Arte Lombarda, 120, 5-27.

Burnett, A. ; Schofield, R. (1998). «An Introduction to the Portrait Medallions on the Certosa di Pavia ». Mann, N. ; Syson, L. (eds), The Image of the Individual: portraits in the Renaissance. London, 55-66.

Carrara, E. (2001). « Vasari e Borghini sul ritratto : gli appunti pliniani della 'Selva di notizie'; ms. K 783.16 del Kunsthistorisches Institut di Firenze ». Mitteilungen des Kunsthistorischen Institutes in Florenz, 44, 243-91.

Chancel-Bardelot, B. de (2002). «Hommes illustres en médaillons ». Berry Magazine, 62, 20-4.

Chastel, A. (1989). Mythe et crise de la Renaissance. Genève ; Paris.

Chastel, A. [1984] (1994). Musca depicta. Milan.

Chatenet, M. [2001] (2013). Chambord. Paris.

Chédeau, C. (1997). "L'église Saint-Michel de Dijon ». Congrès archéologique de France, 152, 277-96.

Contenson-Hallopeau, M.-Laure de (1986). «Couturesur-le-Loir, le manoir de La Possonnière ». Congrès archéologique de France, 139, 178-89.

Corvisier, C. (2007). « L'hôtel Labenche de Brive-la-Gaillarde ». Congrès archéologique de France, 163, 419-23.

Cospérec, A. (1994). Blois, la forme d'une ville. Étude topographique et monumentale [PhD Dissertation, Tours, 1993]. Paris.

Crépin-Leblond, T. (2002). Le château de Blois. Paris.

Crépin-Leblond, T. (2005). " Le manoir d'Ango à Varengeville-sur-Mer ». Congrès archéologique de France, 161, 339-44.

Crépin-Leblond, T. (2011). "Villefranche-de-Rouergue, château de Graves ». Congrès archéologique de France, 167, 438-42.

Crépin-Leblond, T. (2012). « L'emploi de la terre cuite et de la céramique dans le décor monumental en France au XVle siècle ». Boudon-Machuel, M. (éd.), La sculpture française du XVIe siècle. Études et recherches $=$ Conference Proceedings (Paris, 1-2 October 2009; Troyes, 3 October 2009). Manosque, 56-61.

Cueille, S. ; Dubin, A. (2009). Le château de Montal. Paris.

David, H. (1929). " Une chapelle du XVle siècle à NotreDame de Beaune, la chapelle de Bouton ». Congrès archéologique de France, 91, 289-316.

David, H. (1933). De Sluter à Sambin, essai critique sur la sculpture et le décor monumental en Bourgogne au 
XVe et au XVle siècle [PhD Dissertation, Paris, 1932] Paris.

Debuiche, C. (2012). « Un édifice toulousain de la Renaissance entre France et Espagne. L'hôtel de Bernuy ». Lugand, J. (éd.), Les échanges artistiques entre la France et I'Espagne (XVe-fin XIXe siècles) = Conference Proceedings (Toulouse, 27 November 2007, 2 March 2009, 11 May 2010). Perpignan, 35-54.

Debuiche, C. (2016). Architecture et culture savante à Toulouse à la Renaissance [PhD Dissertation]. Toulouse.

Deswarte-Rosa, S. (éd.) (2004). Sebastiano Serlio à Lyon, architecture et imprimerie. Vol. 1. Le Traité d'architecture de Sebastiano Serlio, une grande entreprise éditoriale au XVIe siècle. Lyon.

Di Battista, R. (1998-1999). "La porta e l'arco di Castelnuovo a Napoli ». Annali di architettura : rivista del centro internazionale di studi di architettura Andrea Palladio di Vicenza, 10-11, 7-21.

Didier, F. ; Guillaume, J. (2000). « Hic terminus hæret». Le château d'Oiron et son cabinet de curiosités. Paris, 13-123, 296-309.

Didon, C. (1996). Châteaux, manoirs et logis. Le Lot. Chauray.

Droguet, V. (2007). «L'hôtel de ville de Beaugency et sa restauration au XIXe siècle ». Bulletin Monumental, 165(1), 99-108.

Dubin, A. ; Rebière, J.-L. (2011). Le château de Gramont. Paris.

Duhem, S. (2012). Impudeurs \& effronteries dans l'art religieux breton, XVe-XVIIIe siècles. Brest.

Étienne, C. ; Pagazani, X. (2003). « Le manoir de Bévilliers à Gonfreville-l'Orcher ». Beck, B. ; Bouet, P. ; Étienne, C. ; Lettéron, I. (éds), L'architecture de la Renaissance en Normandie $=$ Conference Proceedings (Cerisy-laSalle, 30 September-4 October 1998). Condé-surNoireau ; Caen, t. 2, 299-304.

Esquieu, Y. (éd.) (2003). Du gothique à la Renaissance. I-Architecture et décor en France (1470-1550) = Conference Proceedings (Viviers, 20-23 September 2001). Aix-en-Provence.

Faisant, É. (2010). Fontaine-Henry. Caen

Faisant, É. (2013). L'architecture à Caen du règne de Charles VIII au début du règne de Louis XIII [PhD Dissertation]. Nantes.

Fillion, B. (2003). « L'hôtel Berthelot, 24, rue de la Chaîne, cinq cents ans d'histoire ». Pon, G. ; Debiès, M.-H. ; Fillion, B. (éds), Le Centre d'Études supérieures de Civilisation médiévale (1953-2003). Turnhout, 7-29, 117-19.

Gillot, D. ; Lettéron, I. (1996). Rouen. L'hôtel de Bourgtheroulde, demeure des Le Roux. Rouen.

Guillaume, J. (1969). «Chenonceaux avant la construction de la galerie. Le château de Thomas Bohier et sa place dans l'architecture de la Renaissance ». Gazette des Beaux-arts, 110(73), 19-46.

Guillaume, J. (1983). "L'ornement italien en France. Position du problème et méthode d'analyse ». $L a$ scultura decorativa del primo Rinascimento $=A t t i$ del I Convegno Internazionale di studi (Pavia, 16-18 September 1980). Rome, 207-12.

Guillaume, J. (1996). « Talmont-Saint-Hilaire, les Granges-Cathus ». Congrès archéologique de France, 151, 259-68.
Guillaume, J. (1999a). « Le château de La Rochefoucauld, la Renaissance ». Congrès archéologique de France, 153, 231-43.

Guillaume, J. (1999b). "Le château de Puyguilhem ». Congrès archéologique de France, 156, 281-91.

Guillaume, J. (2003). "Le temps des expériences. La réception des formes 'à l'antique' dans les premières années de la Renaissance française ». Guillaume, J. (éd.), L'invention de la Renaissance. La réception des formes "à l'antique" au début de la Renaissance $=$ Conference Proceedings (Tours, 1-4 June 1994). Paris, 143-76.

Guillaume, J. (2004a). «Oiron au XVle siècle, le château et l'église ». Congrès archéologique de France, 159, 201-8.

Guillaume, J. (2004b). "Thouars, collégiale NotreDame». Congrès archéologique de France, 159, 311-21.

Guillaume, J. (2006). Le château de Bonnivet. Entre Blois et Chambord, le chaînon manquant de la première Renaissance. Paris..

Guillaume, J. (2012). «Les débuts de l'architecture de la Renaissance à Tours ». Chancel-Bardelot, B. de ; Charron, P. ; Girault, P.-G. ; Guillouët, J.-M. (éds), Tours 1500, capitale des arts = Exhibition Catalogue (Tours, 17 March-17 June 2012). Paris; Tours, 90-104.

Guillaume, J. ; Lamirault-Sorin, S. (2003). « Le château d'Ussé». Congrès archéologique de France, 155, 369-85.

Hervier, D. (1977). Pierre Le Gendre et son inventaire après décès, une famille parisienne à l'aube de la Renaissance. Étude historique et méthodologique [PhD Dissertation, Paris, 1973]. Paris.

Jestaz, B. (2003). « Les rapports des Français avec l'art et les artistes lombards, quelques traces ». Contamine, P. ; Guillaume, J. (éds), Louis XII en Milanais = Conference Proceedings (Tours, 30 June-3 July 1998). Paris, 273-303.

Jongleux, E. (1931). Une visite à l'hôtel de Cujas, Musée du Berry. Bourges.

Journé, E. (2001). "La chapelle de Pagny-le-Château ». Recueil des travaux du Centre Beaunois d'études historiques, 19, 17-39.

La Picardie historique et monumentale. 1. Arrondissement d'Amiens (1893-1899). Amiens; Paris.

Lacroix (1881). "La maison des Têtes à Valence ». Bulletin de la Société d'archéologie et de statistique de la Drôme, XV, 81-94, 215-23, 333-41.

Le Pogam, P.-Y. (2007). « Le thème de la 'tête de feuilles' aux XIIle et XIVe siècles. L'humanisme gothique à l'épreuve ?». Baron, F. ; Bresc-Bautier, G. ; Le Pogam, P.-Y. (éds), La sculpture en Occident. Études offertes à Jean-René Gaborit. Dijon, 33-45.

Lefèvre-Pontalis, E. (1916). "Paray-le-Monial, église, hôtel-de-ville et musée ». Congrès archéologique de France, 80, 53-65.

Leveel, P. (2003). «L'ancien hôtel de la Bourdaisière ou du Gouvernement (XVIe-XIXe siècles)». Bulletin de la Société archéologique de Touraine, 49, 129-40.

Lichtenstein, J. ; Michel, C. (éds) (2006). Conférences de l'Académie royale de peinture et de sculpture. Tome I, Les conférences au temps d'Henry Testelin, 1648-1681. Paris. 
Louis, J. (2012). « Nicolas de Leyde et le thème du buste accoudé au nord des Alpes ». Dupeux, C. ; Recht, R. ; Roller, S. (éds), Nicolas de Leyde, sculpteur du XVe siècle. Un regard moderne $=$ Exhibition Catalogue (Strasbourg, 30 March-8 July 2012). Strasbourg, 114-19.

Mérindol, C. de (1996). « La disposition des bustes et de la statue équestre sur la façade de l'hôtel Jacques-Cœur à Bourges ». Goldman, P. ; Roth, C.-E. (éds), En Berry, du Moyen-âge à la Renaissance. Pages d'histoire et d'histoire de l'art. Bourges, 245-51.

Munoz, S. (2012). " Architecture et figure sculptée dans la première moitié du XVIe siècle. Les têtes en médaillon dans les monuments toulousains ». Boudon-Machuel, M. (éd.), La sculpture française du XVIe siècle $=$ Conference Proceedings (Paris, 1-2 October 2009; Troyes, 3 October 2009). Manosque, 80-91.

Munoz, S. (2016). Célébrer et paraître. Les têtes en médaillon sculptées dans l'architecture de la Renaissance en France [PhD Dissertation]. Toulouse.

Munoz, S. (2018a). « Girolamo Della Robbia (Florence, 1488-Paris, 1566). Buste d'Alexandre ». Hémery, A. ; Julien, P. (éds), Toulouse Renaissance $=$ Exhibition Catalogue (Toulouse, 17 March-24 September 2018), 119-23.

Munoz, S. (2018b). « Médaillons sculptés ». Boudon-Machuel, M. (éd.), Le château d'Azay-le-Rideau. Paris, 85.

Noblet, J. (2003). «Les collégiales castrales à vocation funéraire en région Centre. L'affirmation d'un statut social par l'architecture ?». Esquieu 2003, 105-21.

Noblet, J. ; Rapin, T. (2001). « L'évolution de la façade de la cathédrale de Tours (XIle-XVle siècles)». Bulletin de la Société archéologique de Touraine, 47, 67-77.

Pagazani, X. (2018). « Le château d'Assier en Quercy : un chaînon manquant de la Renaissance ». Hémery, A. ; Julien, P. (éds), Toulouse Renaissance $=$ Exhibition Catalogue (Toulouse, 17 March-24 September 2018), 119-23.

Pagazani, X. ; Salmon, J. (2018). «Le chantier». Boudon-Machuel, M. (éd.), Le château d'Azay-le-Rideau. Paris, 48-61.

Papillault, R. (1996). Les hôtels particuliers du XVIe siècle à Toulouse. Toulouse.

Passoni, M.C. ; Stoppa, J. (2000). Il tardogotico e il Rinascimento. Milan..

Pérouse de Montclos, J.-M. (1995). «Troyes, hôtel de Marisy ». Pérouse de Montclos, J.-M. (éd.), Le guide du patrimoine. Champagne-Ardenne. Paris, 386.

Pflieger, M. (2015). Le chœur de l'église Notre-Dame des Marais de La Ferté-Bernard. Une fenêtre ouverte sur la Renaissance 1535-1569 [PhD Dissertation]. Tours, 33-57.
Ponsot, P. (1990). «Le château de Villesavin ». Bulletin monumental, 148, 384-85.

Prache, A. (1989). " Notre-Dame de Semur-en-Auxois ». Congrès archéologique de France, 144, 291-301.

Prunet-Tricaud, M.-R. (2014). Le château d'Assier en Quercy. Une œuvre majeure de la Renaissance retrouvée [PhD Dissertation, Paris, 2003]. Paris.

Renaud, B. (2003). « Deux édifices riomois de la première Renaissance. L'hôtel de Cériers et la maison dite des Consuls ». Congrès archéologique de France, 158, 393-402.

Ribault, J.-Y. (1973). « À propos du maçon Jean Hudde et de l'Hôtel Lallemant. Notes sur la Première Renaissance à Bourges ». Cahiers d'archéologie et d'histoire du Berry, 35, 66-82.

Ribault, J.-Y. (1995). « La Verrerie ». Pérouse de Montclos, J.-M. (éd.), Le guide du patrimoine. Centre, Val de Loire. Paris, 661-2.

Ribault, J.-Y. (2001). Le palais de Jacques Cœur, Bourges. Paris.

Rioult, J.-J. (2009). « La Martyre, église Saint-Salomon ». Congrès archéologique de France, 165, 143-9.

Roudié, P. (1975). L'activité artistique à Bordeaux, en Bordelais et en Bazadais de 1453 à 1550 [PhD Dissertation, Bordeaux, 1969]. Bordeaux.

Roudié, P. (1981). « Le maître de Biron et les bustes de Montal ». Bulletin Monumental, 139, 233-9.

Salet, F. (1953). « L'église Saint-Pierre de Dreux ». Bulletin monumental, 111, 274-5.

Schofield R. (1999). « The Certosa Medallions : An Addendum ». Arte Lombarda, 127, 74-84.

Séraphin, G. (1990). Cahors et la vallée du Lot. Mercuès.

Thiéry, Y. (1935). « Hôtels et monuments de la Renaissance à Riom ». Bulletin Monumental, 94, 460-6.

Tollon, B. (1993a). « Cahors, l'archidiaconé Saint-Jean ». Congrès archéologique de France, 147, 87-98.

Tollon, B. (1993b). « Nicolas Bachelier et la sculpture toulousaine au milieu du XVle siècle ». Bresc-Bautier, G. (éd.), Germain Pilon et les sculpteurs français de la Renaissance $=$ Conference Proceedings (Paris, 26-27 October 1990). Paris, 362-84.

Tollon Bruno (2014). "Gramont, château ». Congrès archéologique de France, 170, 227-33.

Vallery-Radot, J. (1957). "L'église Saint-Loup à Auxon ». Congrès Archéologique de France, 113, 297-302.

Vasselin, M. (2003). « La façade de la maison des Chevaliers à Viviers ». Esquieu 2003, 181-92.

Verdier, T. (éd.) (2012). Bournazel, un château de la Renaissance en Rouergue. Bournazel.

Vignier, F. (1989). « Château de Chailly ». Congrès archéologique de France, 144, 41-6. 